\section{ORIGITAT COMDUUTICATIONS.}

\section{LETTSOMIAN LECTURES FOR 1853.}

By EDWARD WILLIAM MURPHY, M.D., Professor of Midwifery in University College, and Obstetric Physician to University College Hospital.

LECTURE SECOND.

SECOND AND THIRD STAGES OF hABOUR : ERRORS OF MANAGEMENT WHICH MAT BE COMMITTED.*

\section{Mr. President and Geytlemen,}

I wouLD wish this evening to direct your attention to the next stage of parturition: and, having briefly pointed out the manner in which the child is forced through the pelvis, and the difficulties which oppose themselves, I shall endeavour to prove to you the errors that may be and are committed in the management of this stage-mistakes which too often lead to the most disastrous results.

As soon as the mouth of the womb is completely dilated, or at least when the resistance of the cervix is overcome, a rery remarkable change takes place in the expulsive cfforts of the uterus. Hitherto nature has excrcised the utmost caution in applying the force at her command ; and every means has been used to control the power of the fundus uteri, so long as the tissues of the cervix were unfolded and unprepared to yicld to it. But now that difficulty is overcome; and we not only find these expulsatory muscles exerting a much greater force, but the whole of the respiratory muscles are called in to aid the expulsive effort. Hence the full inspiration which precedes the pain, and the prolonged deep-toned expiration, which has obtained for these pains the old-fashioned but well known appellation of "groanings". This increased power is fully required to effect the object now to be accomplished; the head of the child has to pass through an osseous cavity so irregular in its form, and so limited in its space, as to need it all. It is not easy for the practitioner, who attends an ordinary labour, to realize to the mind's eye the difficulty which is being overcome, or the force necessary to advance the head; but if, in the dissecting or the dead-room, he endeavoured to force the head of a still-born child through the pelvis, he would soon be convinced of it. It sometimes happens that women die suddenly in this the second stage of labour ; and in the post mortem inspection, a very great effort is required to extract the hend from the pelvic cavity. I have known it to require all the strength a person could use, before it was accomplished.

Such then being the case when, on the one side, there is great power called into action, and, on the other, great resistance, the utmost ingenuity is required so to regulate these opposing forces, that no injury may arise in the struggle that takes place. The power is still to a certain extent controlled; the liquor amnii may not yct have escaped; and if it has not, it resists, but to a much less extent, the force of the fundus; besides, the amount of force which is used is accurately measured by the resistance. In cases of disproportion, where the resistance is great, the contractions of the utcrus, at first vigorous and powerful, become afterwards weaker, return at longer intervals, and sometimes cease altogether until the effects of the struggle have subsided : but if the resistance be only moderate, the pains continue of the same strength, return at equal intervals, and are nerer suspended. In order, however, to overcome the difficulties presented by the pelvis, an amount of mechanical contrivance is displayed, as necessary as it is beautiful.

To illustrate this, allow me to recal to your attention the peculiar form of the pelvic cavity. You are aware that the inlet and outlet of the pelvis are in planes which, if prolonged, would meet at an angle ; or, in other words, that the axis of the brim and outlet intersect at a point within the

- This Lecture was delirered before the Medical Society of London, on Yareh 16th, 1859. cavity. The widest space of the inlet is in the transverse, that of the outlet in the antero-posterior direction. The head of the child enters the pelvis in the axis of the brim, moving downwards and backwards; it emerges in that of the outlet, that is, downwards and forwards. So long as it is passing in the axis of the brim, the inequalities of the pelvic cavity oppose themselves; when entering that of tho outlet, the soft tissues which close it are the chief points of resistance.

We find also, that the form of the pelvic cavity is such that the head in its transit must take a spiral direction. If, for instance, the pelvic cavity be considered as a series of planes, it will be found that the widest space in each plane, as we descend, changes from the transverse to the anteroposterior measurement : the head in its descent, therefore, must describe a spiral curve, and the pelric cavity becomes a kind of female screw.

The advantage of this formation must be obvious; the very inequalities of the pelvis, which are designed to support the superincumbent viscera, are so arranged, that they also form a mechanic power to aid the passage of the child. It serves also another purpose-it obliges the head to assume that direction which is most farourable for its expulsion. The most common position which the head presents when it enters the pelvic cavity is that in which the occiput lies anterior to the transverse axis; this is also the most favourable for expulsion, because the back of the head has to glide only a short distance along the curve, in order to pass beneath the arch of the pubis, and afford room for the anterior part to complete its descent. It sometimes happens, however, that the head presents differently. The forehead, for instance, may be anterior, and take the place of the occiput: if the head continued to descend in that direction, it must be forced very much lower down before any portion could leave the pelvic cavity; and being still in the axis of the brim, would be strongly resisted by the coccyx and perinaum, the coccyx especially, and the muscles attached to it, powerfully opposing themselves. But the screw-formation of the pelvis generally prevents this ; because, as the head descends, the occiput, which lay posterior to the transverse axis at its entrance, is rotated forwards along the curre until it becomes anterior to it ; thus securing the important advantage that, no matter what may be the direction of the head at the brim of the pelvis, it must assume, on its transit, that which is the most favourable for its expulsion.

The same rule applies to other presentations than that of the rertex. The face, for examplc, may present; and if so, the chin lies forwards, just as the occiput in the former instance ; consequently, the chin has only a short distance to pass before it escapes under the arch of the pubis, in order to give room for the remainder of the head to emerge from the pelvis. The chin, however, may be directed backwards in the first instance; and if it continued so, the cranium, which is anterior, would pass along the arch like a wedge, the forehead first, then the parietal portion, which must greatly increase the difficulty of expulsion. The form of the pelvis, however, generally prevents this; because, even in this unfavourable position, the chin is often moved forward in its descent, just like the occiput in occipitoposterior positions.

In preternatural positions the same rule is applicable. If the breech present, the most favourable position for delivery is when the back of the child is anterior, corresponding to the abdomen of the mother; but if this be reversed, so that the back lies posterior to the transverse axis, the sacrum nearly corresponding to the sacro-iliac articulation, then the same rotation takes place as in the former instances; the back is rotated forwards, and the deviation is corrected. Thus it will be seen that the peculiar form of the pelvic cavity, limited in its space and irregular though it be, affords the most striking illustration of mechanical contrivance, and is a noble proof of the design of a master mind, who can make these very difficulties the most efficient means of accomplishing his purpose.

The manner in which the head of the child passes through the pelvis, also deserves attention. It not only soeks the 
widest space, but passes through on the principle of a wedge; its least measurement is first presented to the pelvic cavity, and is forced forward in advance of wider portions. For instance, the antero-posterior axis of the head is never parallel to or coincident with the oblique axis of the brim; it cuts it at an angle more or less acute; the occipital end descends, the frontal rises, and thus it passes through the brim. So also the longest transverse axis of the head does not coincide with the opposite oblique axis of the pelvis; the parictal extremity next the pubis descends lower than that corresponding to the sacrum. Thus the head, as a wedge, is forced into the pelvic cavity, which in many instances it expands to a greater or less extent.

In this brief outline of the mechanism by which the difficulties presented by the human pelvis are orercome, I have endeavourel to use the plainest language, and to address myself ruther to those who have not made this sulject their study, than to those of my professional brethren who are perfectly conversint with it. I trust, therefore, that they will pardon this superficial detail, as my wish is not so much to enter into the minutic of this mechanism, as to point out with sufficient clearness where practical errors are too frequently committed.

In the description just giren, it is assumed that the pelvis is perfectly well formed, and that no disproportion exists between it and the head. In such a case, assistance or interference is no more needed than in the first stage of a healthy labour. Nature is omnipotent, and therefore there is no oceasion for superior skill: the highest sagacity is shown in doing nothing.

But, unfortmiately, the pelvis is not always perfectly well formed, and the proportion between it and the head is too frequently deranged by many causes. In the consideration of this subject, it cinnot be too strongly impressed upon the mind, that civilisation and its vices bring with them the same penalties here as in other instances; and if, in the study of disease, we can trace its causes to habits which are the result of our artificial existence, so in this natural process of parturition, we find the same causes in operation to deprive it of its proper character. The so-called "natural labour" is no longer natural, and must be viewed as a deviation from normal parturition, just as much as disease is a deviation from health : the one requires aid just as much as the other, and equally needs a sound scientific medical elucation.

I shall first direct your attention to the more trifling impediments to delivery, and then to those serious obstacles which depend upon disproportion.

The pelvis may be perfectly well formed, and yet the head maty, through violence of the pains, he forced into the cavity in such a manner that the frontal or anterior part descenrls lower than it should. The consequence is, that the longitudinal axis of the head lies obliquely across, and becomes fixed in the pelvic cavity; the head makes no further advance; and, although the pains are quite adequate for the purpose, no progress is made in the labour. The educated practitioner at once recognises and corrects this displacement: nothing is more easy. But let us suppose the woman to be in the hands of an ignorant person, who knows nothing whatever about the positions or displacements of the head; who thinks that she knows a great deal, quite sufficient for all practical purposes, when she can distinguish the hend from the breech. Under such circumstances, the case becomes one of difficult labour; the pains continue fruitlessly for hours, until at length, making no impression, they become weaker, return at longer intervals, and perhaps are suspended. 'The sagacious attendant then decirles that assistance is necessary : possibly indulging in scientific language, she may call it a case of uterine inertia, or perhaps a distorted pelvis, requiring the forceps at least to effect the delivery. Assistance arrives; a vaginal examination is made; the position of the head is corrected; the labour rapidly proceeds to its conclusion without any instrumental aid, and exposes and puts to flight this most learned explanation of the cause of delay and the mode of remoring it.
It would be well if all such blunders could be so easily and so safely corrected; but, unfortunately, it is otherwise. I shall quote another instance, where mismanagement leads to a very different result: for example, when the face prosents. In such instances, when the position is favourable, the chin lying forwards, the delivery is generally easy: when unfavourable, the deviation will correct itself, or may be corrected; but if we suppose the case in the hands of the scientific individual before alluded to, the results are pretty nearly as follows. The presentation is unusual: it is not the head, nor the foot, nor the breech: what, then, is it? Frequent examinations are made to solve the mystery ; the cheek and part of the face which present, already congested and swollen from the pressure of the pelvis, now become much more so; and if no further injury be done to the child, the presentation is arrested : it cannot alter its direction, and so it remains. Labour continues inefficiently for hours; examination after examination is made; and at length, deciding by the rule of time, the midwife comes to the same conclusion as in every other instance. "Everything that could he done was done; but the birth would not come ; therefore, assistance must be obtained." Aid is demanded; the forceps are applied, and the child delivered still born; its face frightfully swollen and disfigured. Thus is one life unnecessarily sacrificed.

Let us suppose a different case-one where the breech descends in place of the head. There are certain cases of male infants where the scrotum has been so compressed as to become greatly swollen. I have known instances where, from constant examinations made to find out what this was, the scrotum has sloughed, and the child has been almost cmasculated. Some year's ago, a highly esteemed medical friend informed me of a case that had just occurred, which, at the time, I believed to be scarcely credible. A tumour of this kind was discovered by a midwife, who immediately sent for a practitioner. Not well understanding it, he obtained a second opinion: neither, however, were very clear as to its nature; but both were perfectly satisficd as to the delay of the labour. By a very simple process of reasoning, they arrived at the conclusion that this tumour must be the cause; and, therefore, that it should be removed. The operation was performed, and the tumour giren to the midwife, who, being very curious to know what it was, closely examined it, and discorered the testes of the child!

Again, there are cases when the breech descends with the back towards the sacrum, in which it is driven down so far that it cannot rotate. An attempt is made to deliver without correcting this error; the limbs and body are brought down; but the great difficulty, the head, remains: this is pressed forwards over the brim of the pelvis, and, being there caught, cannot be moved: powerful but misdirected efforts are made to extract it, but all to no purpose; and assistance is sent for just when it is too late-the child has already ceased to exist.

Let us now turn to the difficulties presented by disproportion between the head and pelvis, constituting what may be truly called "morbid labour". The natural laws which govern parturition are too frequently deranged by morbid causes : for instance, the head may be so enlarged by disease as not to be able to enter the pelvic cavity. Cases have been reported, where the uterus was in action, not for hours, but for days, endeavouring to force the hydrocephalic head into the pelvic cavity; at length it was ruptured; yet, had the existence of this disease been ascertained in time, a trochar would have been sufficient to remove the difficulty, and to save the patient.

The disproportion, however, more commonly exists in the pelvis, because it is so frequently softened by disease. Our civilized habits here play an important part in destroying that beautiful mechanism which nature had contrived for the woman's safety. The osseous system is at birth only in the progress of its development. The supply of the elements of bone to the blood is constantly demanded in the infant and growing child; this is abundantly furnished by human milk, which contains casein in a large proportion. But when the infant receives no milk, or almost nono-is 
reared artificially on starch and sugar, in a hundred forms, and under most high-sounding names-what is the result? The child may grow fat, thus deceiving the parent, and supporting the reputation of the boasted pabulum. Casein is not essential to the formation of fat, but of bone: and the osseous system pays the cost of this mistake; its development is arrested; the bones are softer than they should be, and yield to the forces which act upon them; hence the deformities in those bones which are under such influence. Take, for example, the bones of the limbs which support the body. How many instances of bent knees, curved shins, and crooked ankles, meet the eye of the experienced surgeon in these centres of civilization! So, also, the vertebral column constantly deviates from the correct curve. It was the remark of a very distinguished surgeon, who, in the full career of an extensive practice, had numerous cases brought before him of diseases in females, that, no matter what may have been the derangement for which his assistance was sought, they all agreed in one point - "none of them had straight backs". If, then, the long bones below, and the vertebral column above, give such constant evidence of this unhealthy condition, how can the pelvis escape-the common centre of their motions, acted upon by both, and depending for its strength on the integrity of the arches which the pelvic bones form? The deviations in the pelvis are just as frequent as those of the spine or the ankles; and it is just as liable to deformities.

In all such cases, then (and they are numerous), the argument, that "midwifery necds little education, because parturition is a natural process", totally fails. In the conduct of such labours, education and skill are just as much required as in the treatment of disease; and it is my duty to point out to you the consequences that arise from the neglect of this education.

The deformed pelvis may present difficulties in the brim, the cavity, or the outlet. In the child, the softened bones produce one kind of distortion; in the adult, another ; and this, because the line of gravity in each is different. In the child, it falls anterior to the pelvic cavity ; in the adult, within it : hence the child can never be said to walk erect: its motions resemble rather those of a man when running, and for the same reason: the runner, by throwing his body forwards, brings the line of gravity beyond the pelvis. The effect on the pelvis of the child is to give it the ovate form; because the sacrum is driven down between the thigh-bones, and these, as a counteracting force, press upwards behind rather than upon the pelvic cavity. If the softening take place in the adult, the sacrum is pressed towards the centre of the pelvic cavity, and the thigh-bones push the acetabula upwards and inwards. These combined forces, acting towards a common point within the pelvic cavity, produce that peculiar form called the cordiform pelvis. This latter rariety is attributed, and in many instances justly, to the disease called "mollities ossium"; but I do not think that this is in all cases its cause. It is true, that the deriation in the infunt pelvis arises from a want of carthy matter, which is not supplied; while that in the adult is produced by a disease which takes it away: but I believe that, even in the adult, the unhealthy character of the fool, and its imperfect digestion, may be such, that the blood fails in its supply of carthy matter, and softening of the bone takes place just as in the child. The pelvis, in such cases, however, will be cordiform, and not ovate.

Either of these exceptions to the stindard pelvis may exist, and yet the uterus may have sufficient power to overcome the difficulty, and to expel the child. $A$ longer time may be required for the purpose; but still they may not demaud assistance; all that is asked from the attendant is an extra supply of patience. There are cases, however, where the uterus cannot accomplish its purpose : the difficulty is caused by a distortion which varies with every case ; and thus difficult labours form a series, from the slightest to the greatest. With some, the aid of the forceps is sufficient to relieve the mother, and save the child; with others, the difficulty, and consequent danger to the mother, is so great, that it is necessary to sacrifice the child; and in a thind class of cases, even this dreadful alternative fails in its object, and the question presents itself, whether, in such extreme cases, we are justified in destroying one life for the very equivocal chance of saving another ? or, in other words, when the risk to the mother from any arailable operation is nearly equal, whether we should not select that which gives to the child its best chance of escape ?

All such cases, which require an operation of any kind to be performed, are admitted to demand also skill and knowledge for its performance; they are considered to be the legitimate property of the educated accoucheur. But it never occurs to those who rcason in this way, that these essentials are just as requisite, nay, even more so, to prevent assistance from being demanded, or, if such aid be really called for, to determine precisely the time and the mode of affording relief. In the management of difficult labours, education and skill are required from the moment that labour commences; not when, after days of protracted and useless suffering, ignorance resigns her pretensions. The cases of mismanagement that spring from this mistake, might be named "legion". Either intlammation is suffered to proceed to that extent, that it may terminate in very serious sloughs in the vagina, cause softening of the tissue of the uterus, or possibly extend to the peritoneum, and terminate in the death of the patient; or she becomes exhausted by the mere protraction of intense pain, the uterus loses its tone, and flooding is the result. In either case, a life may be sacrificed.

Let us now consider the important part that ignorance plays in promoting such results. The attendant, who knows nothing whatever of the true characters of the case in her charge, has only one rule to guide her as to its nature-the rule of time. It is assumed that the degree of difficulty is in direct proportion to the time which the labour occupies, and to the progress made within that time. In order, therefore, to decide hy this rule, labour is suffered to proceed far beyond its ordinary length before it is considered difticult; if any progress happen to be made, a still further time is allowed to determine the degree of difficulty. Symptoms of inflammation or exhaustion are beginning to present themselves, but are unnoticed. One effect, however, cannot escape attention-the action of the uterus becomes feeble, or ceases. It is fortunate if aid is then called for, because the patient may be yet saved; but it may be far otherwise. Stimulants given perhaps to increase the pains, only increase the inflammation; or it may be that ignorance assumes the garb of science, administers ergot of rye, and ruptures the uterus. Thus, before the true degree of difficulty is decided upon, the woman may expire.

It is possible, however, that no advance of the child takes place, although the pains have continued incessantly, not for hours, but for days. This is considered a proof of the greatest disproportion, and assistance is consequently required; but when the consultant arrires, it is just possible that he may find no disproportion at all ; that the patient has bcen suffering all this time from what are called "false pains"; and that to remove the cause which produced them, his assistance was needed at the commencement, not at the termination of her sufferings. The case, however, may be most difficult, and the diagnosis so far correct ; but under what a combination of risks is he now called upon to interfere. Inflammation may have made such progress, that any operation for delivery becomes most dangerous; he has, therefore, to weigh in the balance this risk against the equal and opposing risk of further delay. It may be that no inflammation is present, but the woman is exhausted from her extreme suffering, and gives every evidence of constitutional shock; the action of the uterus is growing feeble, it is losing its tone; and consequently the practitioner is haunted by the apprehension of a fatal flooding the moment that the placenta separates. Thus it is that those labours which the educated practitioner would at once recognize as needing assistance, the moment it could 
be afforded with safety, are suffered to proceed without relief so long, that when it arrives it is useless.

This general outline of the serious consequences which follow the mismanagement of difficult labours, is, I trust, sufficient to convince you of the importance of removing the obvious cause-a deficient education. If time permitted me to examine this question more in detail, the proofs vould so accumulate as to become irresistible. I shall only refer to two examples, which will be sufficient for my purpose.

Let us suppose that the impediment exists at the brim of the ovate pelvis : the head has just entered, but cannot pass through it. The moment this difficulty is ascertained, as soon as it is found that the uterus fails in advancing the birth, the intelligent practitioner at once uses means to aid the uterus, because, if the heiul of the child be suffered to remain long wedged betweeu the promontory of the sacrum and the pubis, the soft parts which are interposed may slough. If this occur, a fistula may be estallished between the urethra and vagina on the pubic side, rendering the patient's life miserable from the constant dropping of urine; or the slough may be on the sacral side, penetrating the tissues as far as the peritoneum, and giving rise to all the symptoms of ruptured uterus. Such are the consequences that may arise from this neolect. The intelligent being, however, to whom I have alluded, thinks otherwise ; sufti. cient time has not been given to ascertain what Nature can do; she waits and waits. "Rusticus expectat, dum defluat umnis". At length she calls for aid, just when it is too late. The injury has been done; and if it should happen that the child is delivered safely by the long forceps, nevertheless the patient does not escape, and the case is very probably quoted as an instance of the injury which this dreadful instrument can do.

If we pass from a difficulty in the brim to one in the cavity of the pelvis, it may arise from two very different causes. The pelvis may be slightly cordiform, the planes of the ischia being presserl too much inwards, and the ischiopubic rami too closely approximating. In such a case, time may do much, hecause the head may be gradually so compressed as to adapt itself to this peculiar form, and the pelvis may expand to a certain degrec, so as to allow it to pass. So long, therefore, as the action of the uterus is strong, and any progress is made, there is no occasion to interfere; but if the head cease to arlvance, if the pains become feeble, and still more, if there be the slightest indication of inflammation or exhaustion, interference becomes immeliately necessary, because the constitution of such patients is gencrally feeble, and will not support the pains of labour when wreatly protracted. 'There is, however, a pelvis of a very different kind, which may equally interrupt and prevent the progress of the child; a pelvis which I have elsewhere described as the mesculine pelvis. This variety is not often olserved amongst the inhabitants of large towns, but is common in a hardy peasantry. Women who have been from their childhood aceustomed to masculine exercises, as digring, carrying burdens, lifting weights, etc., are necessarily stronger and more muscular than women generally are. The bones, in their growth, adapt themselves to the difference ; they are larger and more ossified, hence the large bony wrists, and the stout but most unpoetic ankles, of these rustics. The pelvis is under precisely the same influence ; hence it is much more ossified, and assumes the masculine characters ; the pelvic cavity is deeper and more conical than the standard pelvis. In addition to this, the articulations are as firm and unyielding as sutures. It may happen that the large ossified head of a male child is forced into such a pelvis; and, if so, it becomes, in the strictest sense of the term, "impacted". The ossification of the cranium being almost completed, it cannot yicld sufficiently. The constitution of these patients is always vigorous; the action of the uterus is powerful; the pelvis is like a vice. IJence the great risk to be aroided, is inflammation and its consequences. The cautious practitioner will not interfere too promptly in such cases; his object is to use every means $t$, subdue inflammation, to allow time for the head to mould itself to this peculiar form, and thus hope for delivery. Should he not succeed, he must perforate. pe fore two cases are apparently alike cases of impaction. In the former, a successful delivery is accomplished by the forceps ; in the latter, it cannot be done. But how is an ignorant person to decide such a question as this ? She has ignorant person to de her, which is applied indifferently to all cases; that is, to wait as long as she can, and to do nothing. In either case, therefore, mischief must ensue.

I must now beg your attention to the conclusion of this stage of labour. The expulsive power of the uterus has overcome two of its opposing forces-the fibro-elastic tissue of the neck of the womb, and the osseous cavity of the pelvis : there yet remains a third-the perinæum. The pelvis : there fill up the pelvic outlet, together with the coccyx, form the chief support of the pelvic viscera : these must now be expanded sufficiently to allow the head to pass. The power that may be called into action for this purpose is very great; because, as the head passes down between the pillars of the pubic arch, they become a fulcrum against which the occipital portion rests, while the frontal descends upon the perinaum; the head thus forms a lever of the third order. Such a power as this would be extremely dangerous, if called into full and uncontrolled action. Iacerations of the perinæum would be the rule, not the exception. Some provision is therefore necessary to avoid such an accident ; and here we find nature exercising the same caution, and just as provident in securing a favourable dilatation of the perinæum, as we have already seen in the dilatation of the mouth of the womb. The mucous discharge is greatly incrcased in the vagina; the perinaum is much more extensile : and a kind of act of dilatation takes place. Such a provision as this would seem sufficient to place. Sucht accidents ; nevertheless, we observe a further provision in the manner in which the action of the uterus is controlled. Previously, when the head was passing the pelvic cavity, the full power of the uterus was exerted; but now that it presses on the perinaum, the pains become now that it press at first, and do not resume their previous force until the perineum is completely expanded, and prepared to yield. Then, indeed, the most powerful expulsive efforts of the uterus take place, and the severest and most agonizing pains are experienced by the patient. 'The head of the child, also, for a long time oscillates, descending and retreating before it presses fully on the perinaum ; thus, by diminishing irritation as much as possible, the risk of inflammation is avoided. If, however, inflammation commence in these tissues, we have here, also, an illustration of the agency of the reflex nervous function. The irritated nerves are the messengers to convey the intelligence to their comare the messengers the action of the uterus is instantly controlled, and sometimes completely suspended. The irritation being and sometimes complammation subsides; the mucous discharge returns; the perinaum relaxes; the pains resume their original force, and the head is expelled. This is sometimes accomplisl.ed completely, more frequently in part; the occiput remaining protruded for some time before it is quite expelled.

This brief outline is sufficient to point out how and where errors are committed. They are errors either from carelessness or from precipitancy. The perinæum may be ruptured because it is not proyerly supported ; or it may be torn because the head is brought too rapidly over it. The former error, carelessness, certainly cannot be charged against the respectable individual to whom I have so often alluded; because, however the midwife- be she man or woman-may err in other respects, she never fails to give the perinaum her most sedulous care. The whole of her obstetric duties are concentrated upon this one point; and her reputation mainly depends upon her efficiency in this respect. She will support the perinæum patiently for hours. When it becomes intiamed, or, in her own language, "hot and dry", she greases it with lard, and generally succeeds in saving it in an ordinary natural labour; if the labour become difficult, she generally sends for some one else to lacerate it. The perinæum may be sometimes torn from want of attention : but 
it is far more frequently lacerated from precipitancy. On this point, I fear that I cannot confine my strictures to those who have no knowledge of midwifery. It is an old observation, that "a little knowledge is a dangerous thing", and in the case which I am now supposing, a little knowledge is worse than none. When the pains are suspended the cause may be misunderstood ; ergot of rye is given, powerful expulsive efforts are excited, and the perinæum gives way. Or perhaps the practitioner may have some skill in the use of the forceps or vectis; he believes faithfully that a great deal of time is lost in waiting for the return of pains which can be so easily assisted: the instrument is applicd, and the head brought down upon the perinæum, which, being unprepared, of course gives way. This risk becomes a certainty, if unhappily the accoucheur should imagine that the merit of an obstetric, as of a surgical operation, consists in the quickness with which it is done. To remove a stone from the bladder in a few minutes, is a great proof of surgical skill; to remove the head from the pelvis in the same space of time, is equally an evidence of obstetric rashness; the perinæum is torn to a considerable extent, and a serious injury to the patient is the consequence.

To proceed, howerer, with the phenomena which we are observing, let us suppose that the head and shoulders of the child have safely passed over the perinæum. The greatest difficulty is overcome; the expulsion of the body and limbs gives no trouble, and consequently receives but little attention. Yet $I$ know no stage in this process which requires more. In order to render this intelligible, permit me brietly to review what takes place. The womb is partially, but not completely emptied of its contents ; and that contraction of the fundal muscles now commences, which terminates in a state of permanent contraction. Hitherto the contractions and relaxations have been equal; now the degree of contraction greatly exceeds the subsequent relaxation. As the body of the child passes out, this contraction steadily continues, the lower portion of the womb and cervix closing in successively toward the centre, according as it is emptied. Thus, the order in which these fibres contract is clearly seen; the fundus first, then the body, lastly the cervix. Pari passu with these changes in the uterus, a corresponding change is observed in the abdominal muscles. They also contract on the retiring uterus, compress the intestines closely upon it, and by these means the uterus maintains its state of contraction.

If nature were left quite to herself, the body and limbs would, by successive pains, be slowly extruded; and those final efforts which expel the child, would also detach the placenta.

The after-birth might remain loosely in the uterine cavity, or in the ragina, or be expelled with the child : but in any case the risk of hxmorrhage is removed, because, the separation from the uterus being completed, its source is cut off. No draining can occur through its spongy structure ; and the more perfect contraction of the uterine fibres prevents any hæmorrhage from the sinuses.

These facts are sufficient to point out the causes of failure, as well as the errors which may be committed in the management of this stage. Some of these causes depend on the constitution of the patient. The contractile force of the uterus may be diminished; hence its relaxations are greater than they should be, and hæmorrhage is the consequence. Or it may happen that the correspondence between the contractions of the uterus, and those of the abdominal muscles, is lost: the latter may continue in a state of contraction, when the former is relaxing; hence the superincumbent viscera are pressed down upon the yielding fundus, a cup-shaped depression is produced, an inverted action is set up, and invagination follows, which may terminate in complete inversion, as sometimes happens in very rapid labours.

Another, and much more frequent cause depending upon the constitution, exists in the abdominal parietes. In the explanation given, it was assumed that these muscles retained their natural strength; and when they do so, they are quite sufficient of themselves to support the uterus. But far too commonly they are in a perfectly opposite condition : they are almost atrophied : the constant use of stays weakens the tone of these muscles. The intestines are deprived of their proper support, and the natural healthy action of the uterus is deranged: the final contraction of the fundus (a contraction which reduces it to onetenth of its previous size) is not supported ; consequently its relaxation is far too great; hæmorrhage follows; and thus a very obvious cause, easily provided against, may, if neglected, produce the most serious consequences.

The attention of the intelligent practitioner is directed to the expulsion of the body and limbs of the child, just as much as to any other part of the delivery. He is anxious to secure uniform contraction of the uterus; to give it artificially that support which the abdominal muscles cannot afford ; and thus to render the expulsion of the placenta as easy a matter as the expulsion of the child. But if the parturient woman fall into the hands of a person without education, without any knowledge of the phenomena of which she is a witness, what takes place? No attention is paid to the contractions of the uterus; the child is, perhaps, drawn suddenly away from the passages, while the fundus is left to itself. The contractions are consequently deranged; the cervix and body may contract first, and the placenta be of course retained. To remedy this, the funis is pulled from time to time, at first gently, then more strongly, until at length, one of two results follow: either hamorrhage takes place, because the placenta is partially but not completely scparated ; or the fundus uteri is drawn down and inversion is produced. Thus, by mere ignorance, retention of the placenta may be most unnecessarily produced; by further mismanagement it may be followed by hæmorrhage; and even by violence the uterus may be inverted, and the life of the unfortunate patient be the penalty of misplaced confidence.

Time will not permit me to quote examples to illustrate my argument; but this is the less necessary, because I know that the intelligent practitioners whom I address can call to mind in the range of their experience, sufficient instances to support my statements. I trust, however, that in this account of what takes place in labour, from the opening of the womb to the expulsion of the placenta, I have shown sufficiently that it is not everybody that may practise midwifery; and that a most serious and unnecessary sacrifice of human life may be the consequence of entrusting this natural process to ignorant persons. In my next and last lecture, I shall endeavour to point out the remedy for this abuse; and this will lead to the consideration of the new regulations for obstetric education.

Heurittu Street, Carendish Square, A pril 1853.

\section{CASES OF CARDIAC AND ARTERIAL DISEASE.}

By FRFDFRICK J. BLOWN, M.D.

CASE I. DILATATION OF THE AORTA COMMUNICATIYG WITH

a FALSE aNEURISM EXTERNAL TO THE THORACIC PARIETES.

Alexander Frazer, aged 46, a fish-hawker, residing in Chatham, applied to me on 29th August, 1852. His habits were reported to be temperate, and he stated that he never used raw spirits. I learned from him that, during the hopping season of 1850 (which is in September), he was engaged in drawing out a pole, when it suddenly parted from the ground, and he fell flat on his back. He immediately experienced severe pain through the thorax, extending from the middle dorsal vertebra to the sternum. On returning to his home, directly after the accident, he suffered from a burning " red-hot" sensation within the chest, and a cord-like tightness around the body, on a level with the nipples: cough and dyspncea supervened. The poor man attributed the dorsal pain, which continued severe, to rheumatism, and did not apply to a surgeon until February 1851, nearly six months after the accident. 